\title{
Intra-Op Complications: Primary Versus Repeat Cesarean Section
}

\author{
$1{ }^{*}$ Kushboo, ${ }^{2}$ Sipra Singh ${ }^{3}$ Anju Karan \\ ${ }^{1}$ Resident,Department Of Obstetrics \& Gynaecology, Katiharmedical College And Hospital, Karim Bagh, Bihar
}

\begin{abstract}
Introduction: Caesarean section (CS) is one of the most common obstetric procedures worldwide and an increased rate of caesarean section has been observed in recent studies. Maternal mortality and morbidities associated with repeat caesarean section is an important health problem worldwide.The present study aims at knowing the various intraoperative complications encountered during repeat caesarean sections with respect to those undergoing primary CS.

Materials \& Methods: A total of 200 patients who underwent delivery by CS at a tertiary care centre were included in the study. They was then divided into: Group A(100 women undergoing primary CS) and Group B (100 women undergoing repeat CS). Feto-maternal results and intra-op surgical complications were evaluated and compared between the groups.

Results:The mean age of the study subjects was 26.94 years with subjects of repeat CS being significantly older (28.67 vs 25.21 years; $p<0.05)$. Time taken for surgery was significantly long in repeat CS group (55.43 vs 46.89 mins; $p<0.05)$. Complications like presence of Adhesions and thinning of scar was seen in $35 \%$ and $19 \%$ of the subjects with previous $C S$ ( $p<0.05)$.

Conclusion: An increasing number of CSs is accompanied by serious maternal complications. Decreasing the number of cesarean sections is required to decrease relevant complications. Vaginal birth after CS is an option that should be recommended to the patient.
\end{abstract}

Keywords: Intra-op Complications, Primary Caesarean Section, Repeat Caesarean Section

\section{Introduction}

Caesarean section (CS) is a surgical intervention which is done to ensure the safety of the mother and the fetus when vaginal delivery is not possible (emergency CS) or when there is greater danger to the mother or fetus with vaginal delivery (elective CS) [1].Incidence varies from $10 \%$ to $25 \%$ in developed countries [2]. In India the rate of caesarean section delivery has increased from 3 per cent to 10 percent between 1992-93 and 2005-06 (IIPS, 2007) which is lower compared to some developing nations like Brazil and China [1]. But as India is the second most populous country in the world, a small percentage increase affects a huge number of people. Based on DLHS-3 data (2007-2008), the caesarean section delivery rate in India is 9.2 per cent. However, a substantial inter-state variation of CS exists in India. Among the large states, the proportion of women who have undergone caesarean deliveries is the highest in Kerala (31.8 per cent) followed by Andhra Pradesh (29.3 per cent) and Tamil Nadu (23.2 per cent) and the lowest in Rajasthan and Jharkhand (4.2 per cent in both the states) [3]. The rate of CS is higher in urban areas than their rural counterparts for all the states.

After any laparotomy, it is fairly common to develop scar tissue, adhesions and bladder extension. CS holds no exception to this. Multiple CS is associated with more difficult surgeries with increased blood loss compared with a planned second CS. The risk of major complications increase with number of previous CS. Scaring and adhesion formation is known to cause increase in the major complication rates from 4.3 to $12.5 \%$ [4] depending up on the number of previous caesarean section. Intra peritoneal adhesions have an incidence varying from $5.5 \%$ to $42.5 \%$ [5].Women with a history of CS have a higher risk of hemorrhage, placenta previa, uterine rupture,stillbirth in the following pregnancies, all this contributing to the maternal as well as fetal morbidity.

The present study aims at knowing the various intraoperative complications encountered during repeat caesarean sections with respect to those undergoing primary CS.

\section{Material And Methods}

This hospital-based Comparative study was conducted at Department of Obstetrics \&Gyanecology of a tertiary care hospital for a duration of 1 year.

\section{Inclusion criteria:}

All women who underwent one or more caesarean sections irrespective of age and parity including emergency and elective. 


\section{Exclusion Criteria:}

1. All women who have undergone other abdominal surgeries.

2. Women who had other co morbidities which may affect complications.

\section{Sampling Technique \& Sample Size}

Convenience type of non-probability sampling was used for selection of study subjects after taking prior written informed consent. A total of 200 women who underwent Caesarean Section in our hospital were selected. They was then divided into: Group A(100 women undergoing primary CS) and Group B (100 women undergoing repeat $\mathrm{CS}$ ).

\section{Methodology}

We recorded each patient's demographic data and information related to the surgery, such as preoperative and postoperative hemoglobin levels, presence of dense adhesions, presence of wound dehiscence, placenta previa, placenta accreta, bladder and bowel injury, need for hysterectomy, time of hospitalization, uterine rupture, wound infection, operation time, need for blood transfusion, need for intensive care, maternal mortality, and the presence of endometritis. The fetal data recorded were birth weight, fifth-minute APGAR value, and gestational week at birth. Feto-maternal results and intra-op surgical complications were evaluated and compared between the groups.

\section{Operational Definitions}

- Dense adhesion: It was defined as the presence of adhesions detected intraoperatively, extending from the abdominal wall to the bladder or to the front wall of the uterus, not separating easily, and left alone during surgery as much as possible due to the concern that it could cause serious morbidity.

- Placenta previa: Itwas defined as the placenta closing the cervical internal os completely or partially as found on an ultrasonographic evaluation performed in the third trimester. For patients who did not undergo ultrasonography in the third trimester, complete placenta previa covered the lower segment of the uterus and cervix completely and partial placenta previa covered it partially during intraoperative observation.

- Blood transfusion: It was required in cases with an $\mathrm{Hb}$ value lower than $10 \mathrm{~g} / \mathrm{dl}$, when intraoperative estimated blood loss was more than $20 \%$ of the total blood volume, or when the Hb level was lower than $8.5 \mathrm{~g} / \mathrm{dl}$ postoperatively.

- Operation time: It was calculated as the time between anesthesia induction and skin closure.

Statistical Analysis: All statistical calculations were done using computer programs Microsoft Excel 2007 (Microsoft Corporation, NY, USA) and SPSS (Statistical Package for the Social Science; SPSS Inc., Chicago, IL, USA) version 21.A probability value ( $\mathrm{p}$ value) less than 0.05 was considered statistically significant.

\section{Results}

The mean age of the study subjects was 26.94 years with subjects of repeat CS being significantly older (28.67 vs 25.21 years; $\mathrm{p}<0.05)$. No difference was noted between the groups with reference to gestation age $(\mathrm{p}>0.05)$ (Table 1). Time taken for surgery was significantly long in repeat CS group (55.43 vs 46.89 mins; $\mathrm{p}<0.05)$ while no difference was observed in the blood loss during the procedure $(\mathrm{p}>0.05)($ Table 2$)$. Complications like presence of Adhesions and thinning of scar was seen in 35\% and 19\% of the subjects with previous CS $(\mathrm{p}<0.05)$. Placenta previa was also noted in $5 \%$ cases of repeat CS as compared to none in primary CS cases (p-0.06). No difference was noted between the groups with respect to other complications like PPH and extension of uterine incision $(\mathrm{p}>0.05)$ (Table 3$)$.

\section{Discussion}

Modern obstetrics, for medical, social, economic, and legal reasons has witnessed an increase in the primary caesarean section rates everywhere. This has created a common clinical entity of "previous caesarean section" in subsequent pregnancies, giving a high risk pregnancy status to the reference pregnancy. This raises the difficulty of not only deciding the mode of delivery - vaginal birth after caesarean section (VBAC) or elective caesarean section, but also of difficulties in repeat procedure making it a high risk surgical procedure.

In our study the overall complication rate of a primary caesarean section is $18 \%$. The causes of these complication included PPH (12\%) and extension of uterine incision (6\%). In a study by Joseph et al. [1] the overall complication rate of a primary caesarean section is $21 \%$. The causes of these complication included PPH $(14 \%)$ and extension of uterine incision (7\%).In a similar study by Burgholt et al. [6] the overall complication rate was $12 \%$. Häger et al. [7] reported an incidence of $21.4 \%$ while Van Ham et al. [8] reported an incidence of $35.7 \%$ in a retrospective study of data derived from patient records. The incidence of hemorrhage related to CS 
varies in different studies. The rates were $7.9 \%$ in the study by Häger et al.[7] and $10 \%$ in the study by Karlström et al. [8].

The complication rate of repeat CS in our study was 45\%.This included adhesions(35\%), thin LUS (19\%), extension of uterine incision (3\%), postpartum haemorrhage (5\%) and placenta previa/ accreta (5\%). There were no cases of scar dehiscence, uterine rupture and bladder injury in the study group. In a study by Joseph et al. [1], the complication rate was $46 \%$ including adhesions (34\%), thin LUS(17\%), extension of uterine incision(3\%),postpartum haemorrhage (5\%),placenta previa (3\%) and placenta accrete (2\%). In a study by Farkhundah et al. [9] the overall complication rate was 52.23\%. Dense adhesions were found in 65 (27\%) cases, extremely thinned-out lower uterine segment was found in $28(11.6 \%)$ cases, scar dehiscence was seen in $15(6.25 \%)$ cases, ruptured uterus in $4(1.6 \%)$ cases, placenta praevia in $6(2.5 \%)$ cases, morbidly adherent placenta in $2(0.8 \%)$ cases, bladder injury occurred in $2(0.8 \%)$ cases while fetal demise (due to ruptured uterus) occurred in $4(1.6 \%)$ cases.

The average operative time needed for a primary CS was 46.89 minutes while for a repeat CS it was 55.43 minutes $(\mathrm{p}<0.05)$. Similar results with an increase in average operative time for repeat CS cases were also observed by Joseph et al. [1] and Waheed $\mathrm{H}$ et al. [2].

The relative safety of caesarean section deliveries and its perceived advantages relative to vaginal delivery has resulted in a change in the perceived risk benefit ratio, which has accelerated the acceptance for caesarean section. Although, the operation is now safer than in the past because of improvements in anaesthesia, antibiotics and blood transfusion services, a caesarean section still carries a significant risk to the mother compared to a normal vaginal delivery. Complications of caesarean section can result from any number of factors including maternal and fetal health, timing of the procedure, surgical technique, and clinician experience. Repeat caesarean section is associated with additional risks when compared with primary caesarean section [10].

\section{Adhesions}

Although peritoneal adhesions develop in the overwhelming majority of intra-abdominal and pelvic surgery, there is evidence in the literature that suggests that patients having CS may develop fewer adhesions. Adhesions continue to occur despite lower uterine incisions, though less to the anterior abdominal wall compared to classical incisions. The incidence of adhesion development increases with the number of CS performed is shown in many studies [11]. In present study no adhesions were observed in primary CS cases while rate of adhesion formation in repeat CS cases was $35 \%$. Similar rate of adhesion formation were observed in studies by Joseph et al. (34\%) [1], Morales et al. (46\%) [12], Tulandi et al. (24.4\%) [13], Juntunenet al. (27\%) [14]. The most common adhesions found in the group are between bladder and uterus and also between parietal peritoneum and omentum. Majority of these cases were associated with increased bleeding due to increase in raw surface following adhesiolysis and increased operating time.

\section{Thin Lower Uterine Scar (LUTS)}

Despite the advantages associated with the lower segment CS scar, such scars are still relatively associated with poor healing. In present study incidence of thin LUTS was 19\% in repeat CS cases. Juntunen and colleagues [14] reported a significantly higher percentage of thin $(<2 \mathrm{~mm})$ lower uterine segment in patients undergoing their 4th to 10th CS (study group) compared to those having their 1st, 2nd, or 3rd CD (control; OR, 60.4; CI, 18.4-198.3), while $10.1 \%$ of study group had membranous, transparent, or "lacerated" lower segment, none in the control group did. A recent systematic review of 12 eligible studies [15] which included 1834 women in whom ultrasound was used to evaluate the CS scar, reported a $6.6 \%$ rate of scar defect. Addition of sonohysterogram to such evaluation in another study found that a much higher percentage (20\%) had large defects [16]. Therefore, incomplete healing of the low transverse uterine incision as determined by transvaginal ultrasound may occur more frequently than earlier thought. In a study by Joseph et al. [1] the overall incidence of thinned out LUS was $17 \%$. In a similar study the incidence of extremely thinned out LUS was $11.6 \%$ [9] and it was $18 \%$ in a study by Samaretal. [17]

Poorly healed uterine scar might affect the regeneration of the isthmus of uterus and make it thinner, resulting in much thinner lower uterine segment scar in subsequent pregnancy. Thin lower uterine segment scar is likely to rupture during labor. Unsecured prediction of the integrity of the scarred lower uterine segment during labor appears to be one of the reasons for repeat caesarean sections. Several recent reports suggest that USG evaluation of lower uterine segment can be used effectively to assess its integrity to predict the risk of Intrapartum rupture [18,19]. Rozenberg et al. [20] found that LUS thickness correlated inversely with the risk of rupture and concluded that thickness more than $3.5 \mathrm{~mm}$ is protective against rupture. In a study by Samar et al.; [17] they concluded that there is actually no ideal cut off value that can be recommended for clinical purposes, even if the association of LUS thickness and uterine scar defect is strong. A number of studies have demonstrated that the risk of rupture varies inversely with the interval between the previous CS and next pregnancy and considered it to be risk factor for uterine scar dehiscence and rupture. 


\section{Placenta Previa And Placenta Accreta}

In present study the incidence of Placenta previa was $3 \%$ and that of placenta accrete was $2 \%$. Similar observations were also made by Joseph et al. [1] and Waheed et al. [2]. Many studies have highlighted the previous caesarean section as an important risk factor for placenta previa. The risk increased from $0.26 \%$ with aunscarred uterus to $10 \%$ for women with four or more previous caesarean section [21]. According to a study by Getahun et al. [22], the risk of placenta previa was $0.68 \%$ compared to vaginal delivery $(0.3 \%)$. Placenta accreta is a potentially lifethreatening obstetric condition that requires a multidisciplinary approach to management. The incidence of placenta accreta has increased and seems to parallel the increasing CS rate. Women at greatest risk of placenta accreta are those who have myometrial damage caused by a previous cesarian delivery with either an anterior or posterior placenta previa overlyingthe uterine scar. Diagnosis of placenta accreta before delivery allows multidisciplinary planning in an attempt to reduce the potential maternal or neonatal morbidity and mortality [23].

Overall 35\% of women with placenta Previa and one or more previous caesarean sections have placenta accreta. Various studies showed the association of placenta Previa and previous caesarean sections with placenta accreta and hysterectomy. Our study also confirmed the association of previous caesarean section with placenta accreta. The authors of one study found that in the presence of a placenta previa, the risk of placenta accreta was 3\%, $11 \%, 40 \%, 61 \%$, and $67 \%$ [24] for the first, second, third, fourth, and fifth or greater repeat caesarean deliveries, respectively.

\section{Conclusion}

The evaluation of our study data shows a significant increase in maternal morbidity with repeat CSs. Placenta previa and adhesions seem to play a central role in all the risks. This problem can be overcome by identifying patients at risk during pregnancy in peripheral centers and directing these patients to referral centers, especially during the third trimester. Our study, in light of this background, will help us provide information on the probable complications of placenta previa and adhesions in particular, guiding patients away from elective CS and directing them towards vaginal delivery after CS.

\section{References}

[1]. Sheethal Joseph, Dr.SareenaGilvaz. A Comparative Study on Intra Operative Problems during Primary versus Repeat Caesarean Sections. Sch. J. App. Med. Sci., 2016; 4(2A):303-310.

[2]. FkharunissaWaheed, QamarunissaMuhabat, Raheela Baloch, Waqarunissa Ahmed. Maternal complications in repeated caesarean section. Innovative Journal of Medical and Health Science 6:2 March - April (2016) 49 - 52.

[3]. Sancheeta Ghosh, KS James; Levels and Trends in Caesarean Births: Cause for Concern? , Economic\& Political Weekly EPW, $2010 ; 5$.

[4]. Nisenblat V, Barak S, Griness OB, Degani S, Ohel G, Gonen R; Maternal complications associated with multiple cesarian deliveries. Obstet Gynecol. 2006; 108(1):21-6.

[5]. Myers SA, Bennett TL; Incidence of significant adhesions at repeat caesarean section and the relationship to method of prior peritoneal closure. JReprod Med. 2005; 50(9):659-62.

[6]. Bergholt T, Stenderup JK, Vedsted-Jakobsen A, Helm P, Lenstrup C. Intraoperative surgical complication during cesarean section: an observational study of the incidence and risk factors. ActaObstetGynecol Scand. 2003;82(3):251-6

[7]. Häger RME, Daltveit AK, Hofoss D, Nilsen ST, Kolaas T, ØianPål\& al; Complications of cesarean deliveries: Rates and risk factors. Am J ObstetGynecol 2004; 190(2):428-34.

[8]. Karlström A, Lindgren H, Hildingsson I; Maternal and infant outcome after cesarean section without recorded medical indication: findings from a Swedish case-control study. BJOG 2013; 120(4):479-486.

[9]. FarkhundahKhursheed, Pushpa Siri chand, Nasreen; Intraoperative Complications Encountered in Patients with Repeat Cesarean Section JLUMHS 2009; 08 (01).

[10]. Shumaila Zia, Muhammad Rafique; Intra-operative complications increase with successive number of cesarean sections: Myth or fact. ObstetGynecol Sci. 2014; 57(3): 187-192

[11]. Awoniyi O. Awonuga, Nicole M. Fletcher, Ghassan M. Saed, Michael P. Diamond; Postoperative Adhesion Development Following Cesarean and Open Intra-Abdominal Gynaecological Operations A Review. Reprod Sci. 2011; 18(12): 1166-1185.

[12]. Morales KJ, Gordon MC, Bates GW; Jr Post cesarean delivery adhesions associated with delayed delivery of infant. Am J Obstet Gynecol. 2007;196(5):461.e461-e466

[13]. Tulandi T1, Agdi M, Zarei A, Miner L, Sikirica V; Adhesion development and morbidity after repeat cesareandelivery.Am J Obstet Gynecol. 2009 Jul;201(1):56

[14]. Juntunen K, Makarainen L, Kirkinen P; Outcome after a high number (4-10) of repeated caesarean sections. BJOG. 2004;111(6):561-563.

[15]. Jastrow N, Chaillet N, Roberge S, Morency AM, Lacasse Y, Bujold E; Sonographic lower uterine segment thickness and risk of uterine scar defect: a systematic review. J ObstetGynaecol Can. 2010;32(4):321-327

[16]. VikharevaOsser O, Valentin L; Risk factors for incomplete healing of the uterine incision after caesarean section. BJOG. 2010; 117(9):1119-1126

[17]. Samar Dawood Sarsam ,HebaAbulKadem; Measuring Lower Uterine Segment Thickness Using Abdominal Ultrasound to Predict Timing of Cesarean Section in Women with Scarred Uterus at Elwiya Maternity Teaching Hospital KCMJ 2013; 9(2): 9-13

[18]. Cheung VYT, Constantinescu OC, Ahluwalia BS; Sonographic evaluation of the lower uterine segment in patients with previous caesarean delivery .J Ultrasound Med 2004; 23:1441-7

[19]. Bojold E, Jastrow N, Simoneau J, Brunet S, Gauthier RJ; Prediction of complete uterine rupture by sonographic evaluation of the lower uterine segment .Is J ObstetGynecol 2009; 201:320. 
[20]. Rosenberg P., Goffinet F, Phillipp HJ; Ultrasonographic measurement of lower uterine segment to assess risk of defects of scarred uterus. Lancet 1996; 347 (3): 281.

[21]. Upadhay N, Buist R; Cesarean section: an evolving procedure. Br J ObstetGynaecol 1999;106 (3): $286-92$

[22]. Getahun D1, Oyelese Y, Salihu HM, Ananth CV; Previous cesarean delivery and risks of placenta previa and placental abruption..Obstet Gynecol. 2006;107(4):771-8

[23]. Placenta accreta. Committee Opinion No. 529. American College of Obstetricians and Gynaecologists. ObstetGynecol 2012; 120:207-11.

[24]. Silver RM, Landon MB, Rouse DJ, Leveno KJ, Spong CY, Thom EA, et al.; Maternal morbidity associated with multiple repeat cesarean deliveries. National Institute of Child Health and Human Development Maternal-Fetal Medicine Units Network. ObstetGynecol2006; 107:1226-32

Tables

Table 1. Comparison of Baseline variables among both groups

\begin{tabular}{|l|l|c|c|c|c|}
\hline Variable & Group & N & Mean & SD & p-value \\
\hline \multirow{2}{*}{ Materna Age (years) } & Primary CS & 100 & 25.21 & 4.2 & \multirow{2}{*}{$<0.05$} \\
\cline { 2 - 5 } & Repeat CS & 100 & 28.67 & 4.6 & \\
\hline \multirow{2}{*}{$\begin{array}{l}\text { Gestation Age } \\
\text { (weeks) }\end{array}$} & Primary CS & 100 & 38.7 & 2.9 & \multirow{2}{*}{$\mathbf{0 . 7 1}$} \\
\cline { 2 - 5 } & Repeat CS & 100 & 37.5 & 2.8 & \\
\hline
\end{tabular}

Table 2. Comparison of Blood loss and time for surgery among both groups

\begin{tabular}{|l|l|c|c|c|c|}
\hline Variable & Group & N & Mean & SD & p- value \\
\hline \multirow{2}{*}{$\begin{array}{l}\text { Time taken for } \\
\text { Surgery (mins) }\end{array}$} & Primary CS & 100 & 46.89 & 13.2 & \multirow{2}{*}{$<\mathbf{0 . 0 5}$} \\
\cline { 2 - 5 } & Repeat CS & 100 & 55.43 & 12.89 & \\
\hline \multirow{2}{*}{ Blood Loss (ml) } & Primary CS & 100 & 412.31 & 81.9 & \multirow{2}{*}{$\mathbf{0 . 2 1}$} \\
\cline { 2 - 5 } & Repeat CS & 100 & 433.23 & 77.8 & \\
\hline
\end{tabular}

Table 3. Comparison of various complications among both groups

\begin{tabular}{|c|c|c|c|c|}
\hline \multirow{2}{*}{ Variables } & \multicolumn{2}{|c|}{ Group } & \multirow{2}{*}{ Total } & \multirow{2}{*}{ p- value } \\
\hline & Primary CS & Repeat CS & & \\
\hline \multirow{2}{*}{ PPH } & 12 & 5 & 17 & \multirow{2}{*}{0.13} \\
\hline & $12.00 \%$ & $5.00 \%$ & $17.00 \%$ & \\
\hline \multirow{2}{*}{$\begin{array}{l}\text { Extension of } \\
\text { Incision }\end{array}$} & 6 & 3 & 9 & \multirow{2}{*}{0.50} \\
\hline & $6.00 \%$ & $3.00 \%$ & $9.00 \%$ & \\
\hline \multirow{2}{*}{ Adhesions } & 0 & 35 & 35 & \multirow{2}{*}{$<0.01$} \\
\hline & $0.00 \%$ & $35.00 \%$ & $35.00 \%$ & \\
\hline \multirow{2}{*}{ Thin Scar } & 0 & 19 & 19 & \multirow{2}{*}{$<0.01$} \\
\hline & $0.00 \%$ & $19.00 \%$ & $19.00 \%$ & \\
\hline \multirow{2}{*}{$\begin{array}{l}\text { Placenta Previa/ } \\
\text { Accreta }\end{array}$} & 0 & 5 & 5 & \multirow{2}{*}{0.06} \\
\hline & $0.00 \%$ & $5.00 \%$ & $5.00 \%$ & \\
\hline \multirow{2}{*}{ Blood Transfusion } & 3 & 4 & 7 & \multirow{2}{*}{1.00} \\
\hline & $3.00 \%$ & $4.00 \%$ & $7.00 \%$ & \\
\hline
\end{tabular}

